\title{
El sindicalismo en el contexto de la globalización. Reflexiones a partir del caso venezolano
}

\section{Resumen}

\section{Iturraspe, Francisco*}

El texto tiene por objeto explicar los antecedentes del actual proceso que vive el movimiento sindical venezolano. Con ese objeto intentamos ubicario espacialmente, en el contexto del continente latinoamericano y temporalmente, en la era de la globalización. Adopta como metodología el estudio diacrónico, enfocándose en el tema de la transición. Comienza con una propuesta de periodización de su reciente historia, señalando un progresivo proceso de corporativización de las estructuras de cúpula de las federaciones y confederaciones. Propone algunos aportes sobre el tema de la influencia de la mundialización y, finalmente, realiza algunas propuestas para el debate sobre la actual coyuntura.

Palabras clave: Movimiento sindical, sistema de relaciones laborales, mundialización, corporativismo, Venezuela.

\section{Labor Unions in the Context of Globalization: Relfections on the Venezuelan Case}

\section{Abstract}

This paper discusses the historical background of recent developments in Venezuela's labor movement. With this objective in mind, we attempt to spatially determine the process in the context of the Latin America continent and the era of globalization. We adopt a diachronic study methodology and focus on the theme of transition. We begin with a periodization scheme of recent history, pointing out a progressive process of corporate structuring in the higher management levels of labor federations and confederations. We propose certain advances in the theme of globalization, and finally offer certain proposals for debate as to the present situation.

Key words: Labor movement, labor relations system, globalization, corporative character, Venezuela.

\section{Recibido: 00-11-30. Aceptado: 01-01-15}

Investigador de la Universidad Central de Venezuela, realizó este ensayo en el marco del doctorado en el estudio de las sociedades latinoamericanas, programa de la Universidad de Artes y Ciencias Sociales (Santiago-Chile) y del Instituto de Altos Estudios de América Latina (Sorbonne Nouvelle-Paris III-Francia). panchoiturraspe hotmail.com

Agradezco las observaciones de César Bustamante, Patricio Quiroga y Antonio Romero, señalando - como es común en estos casos - que las opiniones y posibles errores son de exclusiva responsabilidad del autor, sin que de manera alguna puedan ser atribuidos a estos generosos amigos. 


\section{El papel del sindicalismo en el sistema de relaciones laborales}

El sindicalismo tiene en Venezuela un papel importante y cambiante en el sistema de relaciones laborales tanto en el sector público como en el privado y en el sistema político. Sin embargo, desde las concepciones hegemónicas en los medios de comunicación hay permanentes omisiones y -muchas veces- estigmatizaciones de nuestros "sindicatos realmente existentes", más allá de los modelos teóricos en debate.

En cuanto al rol del sindicalismo en la economia, sobre todo en el modelo de industrialización sustitutiva de importaciones, su aporte era fundamentalmente colaborar en el desarrollo del mercado interno a través del aumento del salario real y de la participación de los asalariados en la distribución de la renta nacional.

El presente trabajo se realiza en medio de una coyuntura signada por el intento de un nuevo tipo de intervención del Estado en el movimiento sindical venezolano y la reciente realización el día 3 de diciembre de 2000 de un "referéndum nacional" para convocar a una Asamblea Sindical Nacional con el objetivo de reestructurar el sindicalismo, referéndum con escasa participación popular que abre una nueva etapa de la vida del movimiento ${ }^{1}$. Por nuestra parte, comenzamos de- sarrollando algunas propuestas metodológicas, nos referimos al periodo anterior, tratando de explicar los antecedentes del actual proceso, proponemos una propuesta de periodización de la reciente historia del movimiento sindical, enfocándonos en el tema de la transición, intentamos algunos aportes sobre el tema de la influencia de la mundialización $y$, finalmente, realizamos algunas reflexiones y propuestas sobre la actual coyuntura más que como conclusiones como ideas finales.

\section{El desarrollo sindical: un intento de periodización y los problemas de la transición}

\subsection{Enfoque metodológico}

Consideramos que el análisis del movimiento sindical requiere de -al menos- un triple enfoque:

a. como actor social del proceso histórico

b. como institución del sistema político $y$ del sistema jurídico $y$

c. como sujeto económico del mercado de trabajo y de la distribución del ingreso.

Esas miradas se complementan para darnos las bases de una periodización que atienda a los cambios substanciales que se producen en el proceso de evolución del sindicalismo:

1 El resultado práctico del referendum parece ser la formación de dos grandes grupos sindicales, uno que propugna la disolución de las estructuras existentes, para crear una nueva central de acuerdo a los lineamientos del proceso bolivariano y otro que se propone "relegitimar" y reformar las estructuras actuales a través de elecciones por la base. 
- Desde el punto de vista de actor social, la historia del movimiento sindical es la de la organización y construcción de los instrumentos que intentan representar lo que Melgar Bao (1998) llama la "historia de una clase subalterna" dentro de la dinámica de las sociedades latinoamericanas.

- Desde el punto de vista institucional, lo que Zapata (1993) denomina - en relación con los demás actores - la historia de su "autonomia y subordinación" y su relación con factores externos, o sea otros componentes del sistema de relaciones laborales, del sistema político y del sistema jurídico laboral (1993).

Esta relación institucional en su aspecto dinámico tiene que ver con los conflictos con los otros actores y con la negociación social, cuyo mecanismo típico - al menos hasta ahora - es la negociación colectiva en la que juega un papel fundamental aunque no exclusivo según Parra Aranguren (1997) y que lo vincula directamente a su función económica.

Desde el punto de vista económico, según Chen (1994) y Valecillos (1990), su capacidad de influir en la determinación del precio de la fuerza de trabajo $y$, por ende, en forma directa en la distribución del ingreso nacional, en la conformación del ahorro y la inversión y de la demanda agregada $y$, en forma indirecta, en las opciones tecnológicas y la factibilidad y localización de las inversiones.
Pocos sujetos sociales han recibido la atención que ha merecido en nuestro continente el movimiento sindical. Los análisis periodísticos, históricos, sociológicos, económicos y políticos llenan bibliotecas enteras, pero, sin embargo, también pocas instituciones han sufrido mayores distorsiones en su comprensión.

Por una parte, por la "competencia" de los partidos políticos (que han intentado identificar sus propias historias con las de las organizaciones obreras a las que han, como veremos, en algunos casos creado y, en otros, tratado de controlar) y de los nuevos movimientos sociales (que le disputan su representatividad, su lugar en el imaginario popular y su puesto en la organización de la llamada "sociedad civil") y por otra parte, por a la visión "ideológica" que presentan los grupos dominantes en los aparatos estatales y de comunicación social, con intereses generalmente enfrentados a los que el sindicato representa o deberia representar.

Finalmente, las propias limitaciones del sindicalismo en su crisis política y su relación comunicacional con la sociedad en general y con los trabajadores en particulary por las limitaciones teóricas y metodológicas $^{2}$ (y francamente los prejuicios de clase) de algunos escritos académicos o testimoniales que lo tienen por objeto.

De esta suerte aparecen varios interrogantes relativos a la determinación del período de estudio, al "sujeto social" del cual estamos hablando cuando nos referimos al movimiento sindical y sobre la posi-

2 Uno de los frecuentes problemas en la compresión de nuestros sindicatos es la excesiva "juridización" del Derecho Colectivo en que suelen caer algunos análisis académicos que parecen ignorar los procesos sociales que las normas laborales regulan. 
El sindicalismo en el contexto de la globalización Iturraspe, Francisco

bilidad de hacer un "esquema" común para ese sujeto social para toda América Latina y aplicarlo al caso venezolano.

\subsection{Etapas de la evolución sindical venezolana. El desarrollo sindical: un intento de periodización y los problemas de la transición}

Desde el punto de vista cronológico, la etapa actual comienza con la crisis de los años ochenta, "la década perdida" para América Latina. Este es el periodo que nos hemos detenido a analizar para el caso concreto de Venezuela.

El tiempo en el cual se enfoca en análisis (1980-2000) forma parte de dos períodos de la historia política reciente de Venezuela:

- el que se ha denominado "puntofijista" por la influencia que tuvo en él el acuerdo político entre los partidos Acción Democrática (AD), Comité de Organización Popular Electoral Independiente Partido Social Cristiano (COPEI) y Unión Republicana Democrática (centrista) (URD) después de la caída de Marcos Pérez Jiménez a comienzos de 1958 y que terminó convirtiéndose en un sistema bipartidista dominado por las dos primeras organizaciones políticas hasta que comienza su descomposición en los noventa y culmina en 1999 y

- el que podemos designar provisoriamente como "bolivariano" o "chavis- ta", que se instaura con el triunfo electoral del Frente político de respaldo al Presidente Chávez: Movimiento $V$ República (MVR), Movimiento al Sindicalismo (MAS), Movimiento Electoral del Pueblo (MEP), Partido Comunista de Venezuela (PCV), Patria Para Todos (PPT) (escisión de la Causa R) y otros factores del cual se escindió el PPT en el año 2000) (Polo Patriótico) y la votación y promulgación de la nueva Constitución (año 2000).

En la Tabla 1 resumimos diacrónicamente las relaciones mutuas entre los cambios de la historia politica (segunda columna vertical), las etapas de la evolución sindical (en la primera columna: sindicalismo "partidizado", sindicalismo "neocorporativo" y su actual intento de reemplazo por un sindicalismo "patriótico" u "oficialista") y (en la tercera columna) la progresiva ilegalización del conflicto como un de los ejes del proceso.

a) Tres de los principales problemas del movimiento sindical venezolano- $y$ en general de nuestra sociedad - son:

- el grave subdesarrollo de la autonomia de las organizaciones sociales frente al Estado.

- el también importante deterioro de la democracia en las organizaciones sociales y en la vida política (Iturraspe, 2000) $)^{3}$

- el deterioro de la eficacia de las organizaciones sociales y en particular la

3 Aqui está una de las claves del drama de la Venezuela "puntofiiista". El Estado y los partidos que lo hegemonizaban coparon todos los espacios. A su vez, el Estado era "intervenido" por sectores económicos, políticos y financieros que como verdaderas matias se apoderaban de la renta petrolera. 


\section{Tabla 1}

\section{Proceso histórico del sindicalismo venezolano (1958-2000)}

\begin{tabular}{|c|c|c|}
\hline Movimiento sindical & Historia Política & llegalización del conflicto \\
\hline Sindicalismo Partidizado & Pacto de Punto Fijo (AD, COPEI, UAD) & 1958 \\
\hline $\begin{array}{l}\text { 1958: Avenimiento Obrero } \\
\text { Patronal }\end{array}$ & 59-64 Rómulo Betancourt (AD) & $\begin{array}{l}15 \text { hueigas "legales" y } \\
7 \text { "ilegales" }\end{array}$ \\
\hline División del sindicalismo: & 1961: Constitución & \\
\hline $\begin{array}{l}\text { CTV: partidos del pacto de Punto } \\
\text { Fijo }\end{array}$ & Insurrección armada & \\
\hline CUTV: PCV, MIP etc. & 64-69 Raúi Leoni (AD) & \\
\hline $\begin{array}{l}\text { Centrales socialcristianas } \\
\text { articuladas con FTC(CTV) }\end{array}$ & 69-74 Rafael Caldera I (COPEI) & \\
\hline \multirow[t]{4}{*}{ "ilegalización" de la huelga } & $\begin{array}{l}1973 \text { Reglamentación inconstitucional de la } \\
\text { huelga }\end{array}$ & \\
\hline & Reglamento Caldera I & \\
\hline & 74-79 Carlos Andrés Pérez I (AD) & 1977 \\
\hline & $\begin{array}{l}\text { Comisiones tripartitas-aumentos salariales } \\
\text { por decreto "Gran Vonezuela" }\end{array}$ & $\begin{array}{l}\text { O huelgas "legales" } \\
214 \text { "ilegales" }\end{array}$ \\
\hline $\begin{array}{l}\text { Del sindicalismo partidizado } \\
\text { al neocorporativo }\end{array}$ & $\begin{array}{l}\text { 79-84 Luis Herrera Campins (COPEI) } \\
\text { Viemes negro-devaluación }\end{array}$ & \\
\hline 1980 Manifiesto de Porlamar & Ruptura del modelo de acumulación & \\
\hline Intervención del BTV & Caida del salario real & \\
\hline Estructura sindical & 84-89 Jaime Lusinchi (AD) & 1984 \\
\hline Cada vez más ligada al Estado & $\begin{array}{l}\text { Política económica "proteccionista" } \\
\text { Régimen de cambio diferencial (Recadi) } \\
\text { Aumentos salariales sin incidencia en } \\
\text { prestaciones }\end{array}$ & $\begin{array}{l}\text { o huelgas "legales" } \\
39 \text { *ilegales" }\end{array}$ \\
\hline $\begin{array}{l}\text { Proceso de disolución del } \\
\text { modelo neocorporativo }\end{array}$ & 89-93 Carlos Andrés Pérez II (AD) & \\
\hline $\begin{array}{l}\text { Sindicalismo impotente frente al } \\
\text { deterioro del salario real }\end{array}$ & $\begin{array}{l}\text { "Gran viraje" (apertura) } \\
\text { Febrero de } 1989 \text { Caracazo }\end{array}$ & \\
\hline Precarización & 1990 Ley Orgánica del Trabajo & Después de anulados \\
\hline $\begin{array}{l}\text { Condiciones-medio ambiente de } \\
\text { trabajo }\end{array}$ & $\begin{array}{l}\text { 93-94 Ramón J. Velázquez (AD) } \\
\text { Crisis política }\end{array}$ & $\begin{array}{l}\text { Los articulos del } \\
\text { Reglamento } 1990\end{array}$ \\
\hline Aumento de la marginalidad social & Crísis financiera & 7 huelgas "legales" \\
\hline Cúpulas sindicales integradas & 94-99 Rafael Caldera II (Convergencia-MAS) & 12 "ilegales" \\
\hline Deterioro bipartidismo & Desregulación prestaciones sociales & \\
\hline "concertación" corporativa & Privatizaciơn seguridad social & \\
\hline \multirow[t]{2}{*}{$\begin{array}{l}\text { Sindicalismo corporativo vs. } \\
\text { sindicalismo "patriótico" u } \\
\text { "oficialista" }\end{array}$} & $\begin{array}{l}\text { Intento reglamentario contra el derecho de } \\
\text { huelga } \\
99-(. .) \text { Hugo Chávez (Polo Patriótico) }\end{array}$ & \\
\hline & Proyectos de "Constituyente Sindical" & $\begin{array}{l}\text { Octubre 2000: huelga } \\
\text { petrolera }\end{array}$ \\
\hline
\end{tabular}

CUTV: Central Unitaria de Trabajadores (izquierda).

PCV: Partido Comunista de Venezuela.

MIR: Movimiento de lzquierda Revolucionaria (escisión de izquierda de AD, luego fusionado con el MAS.

FTC: Frente de Trabajadores Copeyanos (fracción sindicai de COPEI)

Fuente: Elaboración propia. 
crisis sindical que constituye uno de los factores de la caida del salario real en el proceso como se señala en el gráfico 1 (Iranzo et alt., 2000).

\subsubsection{La década de los ochenta:} del sindicalismo politizado al neocorporativo

La primera etapa comienza con el Congreso de Proclamar, de la Confederación de Trabajadores de Venezuela, (CTV) a comienzos de la década. Allí los asesores de la CTV, de varias tendencias por cierto, como Domingo Felipe Maza Zavala, Abdón Vivas Terán, Luis Raúl Matos Azócar y el autor de estas notas coincidimos en que la economía venezolana había ido hacia un capitalismo de Estado y que los trabajadores y sus sindicatos debían participar como "socios" del Estado no solamente en la distribución de la riqueza generada, sino también del poder: de alli la idea de cogestión que propuso el Manifiesto de Porlamar, por una parte, y por la otra la necesidad de ampliar la base sindical a través de la creación de sindicatos nacionales por rama de industria ${ }^{4}$. Se trataba de un proyecto democratizador de fortalecimiento del movimiento sindical.

Ese era un movimiento sindical que si bien estaba partidizado le hacía propuestas al Estado, no era parte de él. Pero el proyecto fracasó en parte porque el movimiento sindical no pudo reorganizarse ni acumular fuerzas para imponer su propuesta, en parte por los cambios económicos y políticos nacionales y globales.

Recordemos que estamos también a comienzos del proceso de mundialización y que en ese proceso la economía venezolana se convirtió, pese a los ingentes recursos provistos por la renta petrolera, en exportadora neta de capitales y en una economía con una volatilidad tal que impedía inversiones de largo plazo. La propia industria petrolera nacionalizada comienza una tendencia a realizar grandes inversiones en el exterior. A partir del colapso financiero de febrero de 1983 se manifiesta la crisis del modelo de acumulación y los salarios reales comienzan un declive que durará todo el período, hasta la actualidad.

A su vez el movimiento sindical sufre un fuerte retroceso por la política económica de ajuste del presidente Herrera Campins y con la intervención del Banco de los Trabajadores de Venezuela, (BTV). Este banco, creado por la dirigencia sindical con apoyo de los sindicatos americanos y del propio Estado (que le dio por Ley carácter de banco universal que le permitía captar diferentes tipos de ahorro y otorgar créditos personales, hipotecarios etc.), era una de las bases fundamentales del poder económico de la dirigencia sindical y habia logrado un gran auge en el período anterior.

La incapacidad de influir en la empresa en la determinación del precio de la 


\section{Gráfico 1}

NIVEL DE SALARIOREAL

$(1980-1998)$

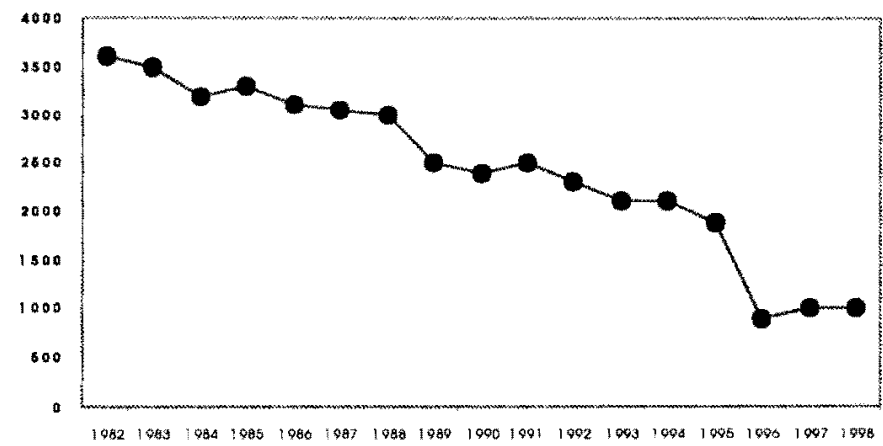

fuerza de trabajo a través de la negociación colectiva lleva a buscar en los decretos y leyes de aumento de salarios o determinación de salarios mínimos el cumplimiento de su acción reivindicativa frente al deterioro pronunciado del salario y el aumento de la marginalización social por el desempleo y las graves distorsiones del mercado de trabajo. Durante el periodo del presidente Lusinchi, un esquema de subsidios y cambio diferencial, Régimen de Cambio Diferencial (RECADI) crea un efímero lapso en cual el empleo aumenta pero a costa de una grave corrupción y disgregación social.

Dentro de las cúpulas sindicales se producen reacciones políticas y éticas, como durante la presidencia de la CTV por el veterano sindicalista petrolero Juan José Delpino, pero la brecha de credibilidad entre los trabajadores y la dirigencia sindical cetevista se profundiza. Los cambios tecnológicos comienzan también aumentar la obsolescencia del modelo y la estructura sindical. La dependencia del Estado en cuanto a recursos financieros y presencia política se acentúa.

Esto no implica que en sectores muy importantes del movimiento sindical haya habido importantes experiencias de autonomía, tanto dentro como fuera de la estructura cetevista. Experiencias de sindicatos independientes con un alto grado de democracia sindical como el Sindicato Nacional de Trabajadores de la Prensa (SNTP), la Unión de Trabajadores de la Industria Textil (UTIT), de su época (sindicato de izquierda combativa del sector, afiliado a la CUTV), el Sindicato de Trabajadores de la Industria Siderúrgica (de Guayana) (SUTIS) Siderúrgica del Orinoco (SIDOR) etc. que no son experiencias aisladas.

De esta manera, se produjo un doble proceso,

a. por una parte importantes movimientos "por abajo", con la radicalización de algunos sectores -no mayoritarios- 
b. por otra parte, las cúpulas sindicales que al comienzo del período estaban "partidizadas" fueron convirtiéndose en algo diferente al finalizarlo: sectores importantes se estatizaron, pasaron - en una esquema neocorporativo - a formar parte del aparato del Estado. |El Presidente y el Secretario General de la principal central sindical, por ejemplo, comenzaron a tener teléfonos interministeriales, como si fueran ministros!.

\subsubsection{La década de los noventa:} del neocorporativismo a la posible disgregación

Políticamente la década comienza, en realidad, en febrero del año anterior con el "Caracazo".

En la relación entre el Estado y las cúpulas del movimiento sindical se agudiza el neocorporativismo al punto que ello comienza a provocar su propia desintegración y se profundiza la deslegitimación de esas estructuras cupulares. Cuando asume - durante el segundo gobierno de Pérez - la directiva de la CTV encabezada por Antonio Ríos, por primera vez la juramentación la hace el Jefe del Estado. El financiamiento de muchas estructuras nacionales y locales, los locales sindicales etc. provienen del presupuesto público. La Ley Orgánica del Trabajo adopta esa tendencia neocorporativa: ¡los fondos sindicales serán fiscalizados, en última instancia, por la Contraloria Ge- neral de la República según el Parágrafo segundo del artículo 442 , como si fueran fondos públicos!

Sin embargo - con la propuesta de "reforma económica" denominada "EI Gran Viraje" - Pérez II prescinde de los partidos (con un sordo enfrentamiento con la propia Acción Democrática) e ignora y margina al Órgano político partidista de conducción sindical, en especial el de AD (Buró Sindical) (Iranzo, 1996). Los condicionamientos de los cambios mundiales entran en contradicción con el esquema político y económico que sostenía el esquema sindical hegemónico. La desintegración del sistema político se acelera y en 1992 se producen dos intentos de insurrección militar y un grave descontento social expresado politicamente en los reiterados "cacerolazos", "apagones" y el desprestigio institucional.

Estamos frente a finalización de la paz laboral que caracterizó largos años de control del sindicalismo oficial desde la derrota guerrillera de los sesenta y, por el contrario, una amplia conflictividad laboral y social, frente a la cual el sindicalismo neocorporativo pierde cada vez más su capacidad de control. En el periodo de Pérez II, desde el 2-2-1989 al 30-5-1993 se producen 282 conflictos colectivos e innumerables desordenes públicos de todo tipo (Romero, 1997b).

Este proceso culmina durante el gobierno de Rafael Caldera: la escuálida "concertación social" que se pretendió

5 El intento del Presidente Carlos Andrés Pérez de establecer ajustes macroeconómicos, apertura y privatizaciones comienza con el "explosivo" aumento de la gasolina que provoca saqueos generalizados en Caracas y otras ciudades y la "ruptura" de la vidriera democrática que significaba Venezuela en el concierto de los paises de la región. 
montar para ampliar la base política del gobierno (pacto Alfaro- líder de AD-con Caldera) y legitimar la privatización de la seguridad social y la "flexibilización" del régimen de prestaciones sociales, era una comedia de equivocaciones: nadie representaba a nadie, ni siquiera - mucho menos - los intereses del propio Estado: fue un elemento muy importante en el hundimiento del sistema.

Como parte del proceso de acelerado deterioro del Estado, los organismos financieros internacionales que financiaron la "reforma" de la seguridad social interviniendo "neocolonialmente" junto con la particiapación descarada de "expertos" de grupos financieros y en especial compañías de seguros que imponian sus criterios sobre las propuestas de los equipos gubernamentales.

La participación sindical fue patética, "intervenida" también por las promesas de un crédito para la formación sindical, las expectativas de montar sus propios negocios previsionales y la participación como asesores sindicales de "expertos" con una lógica "desreguladora" que asumen "tecnocráticamente" la representación de los trabajadores sin el mínimo mecanismo de participación real de las estructuras sindicales $y$, mucho menos, de los trabajadores.

A la privatización y desregulación se acompaña - en una aparente contradicción - la abusiva intervención del Estado en las relaciones colectivas, sobre todo en la represión "institucional-ilegal" de la huelga. Se dicta inconstitucionalmente un Reglamento restrictivo de la huelga, con la presunta participación sindical, aunque en descargo de los sindicalistas podemos afirmar que ningún dirigente fue realmente consultado.

Las cifras de huelgas ilegales tre pan $^{6}$ : la ilegalización del conflicto y la agudización de la tensión social que se había desbordado a comienzos del período con el "Caracazo", deriva en una creciente anomia y un descalabro del sistema bipartidista. Las cúpulas de los sindicatos se convierten - según todas las encuestas de opinión - en la dirigencia más desprestigiada del sistema, aunque estudios serios muestran que en los sectores con tradición sindical sigue existiendo una notable identificación con la "institución" sindicato en grandes empresas como SIDOR, Empresa Estatal Telefónica privatizada en el segundo gobierno de Carlos Andrés Pérez, CANTV y una de las principales empresas de energía eléctrica: CADAFE y con la dirigencia de base (Romero, 1997a).

En el movimiento sindical aparecen reacciones - tardías pero positivas - como por ejemplo, la eliminación de las cláusulas de "enganche" en la industria petrolera $^{7}$ y los "grupos de opinión" sindical que proponen desde dentro y fuera de la CTV las elecciones por la base.

\subsubsection{El periodo de transición}

a) La debacle del sistema bipartidista trae como consecuencia la desarti- 
culación de los partidos tradicionales y las elecciones presidenciales del $\mathbf{9 8}$ con dos "outsiders" como candidatos fundamentales y el triunfo de los que representaba la opción más radical frente al sistema, tanto que había intentado derribarlo por las armas. El comandante Hugo Chávez Frías, que es elegido presidente y diseña una nueva institucionalidad: la Quinta República y es relegitimado este año tras modificar la constitución.

Desde antes de la campaña electoral el actual presidente enfiló sus baterías contra "las cuipulas podridas" del sindicalismo. Sin embargo - como señala Héctor Lucena (2000) "la CTV poco después del triunfo electoral de Hugo Chávez le envió una carta manifestándole su disposición al diálogo y ofertándole su apoyo (EI Nacional 11-12-98). Un reconocimiento del nuevo escenario. La arrogancia cetevista - (CTV) - de otros tiempos desapareció". ¡Sin embargo, su vínculo con el Estado, no podía desaparecer ${ }^{8}$

b) El gobierno ha pretendido desde entonces llevar a cabo elecciones sindicales "desde el Estado", sea por intervención de la Asamblea Constituyente, de la Asamblea Nacional o-actualmente-del Consejo Nacional Electoral.

Las ideologias que predominaron en nuestros sindicatos - $y$ en "sociedad ci- vil" en general - han sido estatistas y ello ha contribuido a que la idea de libertad $y$ autonomía sindical esté escasamente enraizada entre nosotros, en nuestras prácticas, en la conciencia de la mayoria de los trabajadores (Iturraspe, 1999 a).

Pero el conjunto del movimiento sindical, desde su inicio y, a diferencia de otras experiencias más tempranas de otros paises con influencia anarquista, tuvo una fuerte vinculación con las ideas $y$ las organizaciones manxistas, nacional reformistas que devinieron en socialdemócratas, o cristianas, pero en general con un fuerte contenido estatista, dentro del esquema del Estado de bienestar de postguerra primero y del esquema neocorporativo después.

Ahora bien, dentro de este panorama no puede extrañarnos que las normas propuestas con ánimo democratizador, en muchos aspectos, sean contrarias a la idea de autonomía sindical, lo contrario más bien debería sorprendernos.

c) Sin embargo, el esquema adoptado por la nueva constitución en la materia establece en forma amplia las bases de un régimen de libertad sindical.

Por ello, en nuestras discusiones se le suele dar mucha importancia al hecho si las propuestas de democratización se ajustan o no a las normas internacio-

7 La cláusula de enganche es un tipo de cláusula sindical por la cual el sindicato propone a las empresas los nombres de los trabajadores que serán empleados. En la industria petrolera - en especial en los contratistas - el sistema se corrompió generándose abusos permanentes, lo que llevó a la propia dirigencia de las Federaciones a renunciar a la prerrogativa que pasó a ser asumida por comités de desempleados y el Ministerio del ramo del trabajo.

8 Lucena constata en esta cita la actitud proclive al diálogo de la máxima dirigencia sindical y si nos preguntamos por las causas de este cambio podemos proponer la doble hipótesis del deterioro de los partidos que hegemonizaban el aparato sindical y, por otra parte, el paulatino reemplazo de la vinculación con los partidos por la vinculación con el Estado que hemos señalado. 
nales ( $y$ a la Constitución que les otorga él más alto nivel jurídico). Si bien esto es importante para el Estado de Derecho, 10 más importante es definir si este tipo de medidas "desde arriba" puede contribuir a la regeneración del sindicalismo como factor fundamental de una sociedad y de una economía democráticas.

Para ello debemos comprender que el sindicato no es parte del Estado, que hay que respetar los espacios de la sociedad civil. Y lo primero que el Estado debe garantizar, desde ese punto de vista, es la autonomia sindical: la democracia sindical será obra de los propios trabajadores. Este es el esquema adoptado por la Constitución del 99.Sobre ello volveremos en la parte final nuestro trabajo.

\section{Los principales dilemas del movimiento sindical}

\subsection{Movimiento sindical, clase obrera o clase trabajadora}

Ahora bien, pasemos inmediatamente a tratar de definir $i$ de qué hablamos cuando hablamos de movimiento sindical?

En primer lugar deberíamos distinguir el movimiento sindical y clase obrera o clase trabajadora.

No trataremos de trabajar aquí los enfoques de clases sociales para América Latina, pero sí dejar asentado que el sindicato no es la clase trabajadora, sino un movimiento social que intenta organizarla, representar sus intereses económico-sociales $y$, generalmente, pero no siempre, políticos, y a la vez, trata de controlaria y encauzarla, en el marco de los conflictos sociales.
La idea de movimiento sindical es, pues, diferente a la de la acción de clase. No estamos negando que las clases sociales tienen una dinámica histórica, simplemente estamos distinguiendo esa dinámica de la que sin duda forma parte la organización (y también la no-organización: la espontaneidad), la lucha o la pasividad de los trabajadores, las diversas formas de resistencia, de uno de los resultados históricos concretos de la misma.

Es necesario, entonces, comenzar por un primer intento de "desmitificación" o de "desideologización" relativo a nuestro sujeto histórico, frente a las concepciones que establecen que, en forma mecánica o automática, tal partido o tal organización de clase "representan" a esa clase. Cuando nos referimos a la "representación" política el constructo de pensamiento tiene una amplia gama de matices que llevan a la justificación de que determinado grupo político "representa" los intereses históricos de tal sector social, en este caso de la clase obrera, por lo general definido más teórica que concretamente.

Pero, en relación con la representación de los intereses generales y concretos, de las aspiraciones económicas frente a la distribución de la riqueza y la explotación, la "lucha económica", de los valores sociales y culturales frente a los dominantes socialmente, a la salud y la seguridad en los medios ambientes laborales y hábitats patógenos, la lucubración justificadora se torna insubstancial: la organización tal o el sindicato cual, deben en la praxis justificar frente a sus "representados", la defensa de esos intereses. No basta la apelación discursiva a los in- 
tereses "históricos", ni a los "intereses de las mayorías nacionales", ni a la lucha de clases en sentido abstracto.

Los dirigentes sindicales adquieren conocimientos, valores, destrezas, discursos, ideologías que, por una parte, los diferencian de los trabajadores y por otra parte los asimilan a los otros dos factores de las relaciones laborales: los patronos y sus representantes y los funcionarios gubernamentales.

Muchas veces esto produce un claro desclasamiento, aunque en algunos paises como Venezuela, los funcionarios sindicales ni siquiera provienen de la clase trabajadora sino de los cuadros de los partidos "clasistas" o policlasistas, pero que no provienen de los sectores laborales comprometidos en la producción de bienes y servicios. Igualmente, en nuestros países es importante el papel de los "asesores", muchas veces abogados, que suelen apoderarse o secuestrar a la opinión sindical, reemplazando en los mecanismos formalmente "participativos" (pero en realidad corporativos) la opinión de los trabajadores, muchas veces con intenciones loables, pero en general como un mecanismo de reemplazo que, en nuestro país, indefectiblemente marginó la opinión - y los intereses - de los presuntos representados y los sometió al esquema de las políticas del Estado, que a su vez - como veremos - cada vez eran menos definidas por el propio Estado.

Cuando hablamos de movimiento sindical no estamos hablando, pues, de la clase trabajadora sino de organizaciones que pretenden - y a veces lo logran, y a veces no, y con diversos grados entre ambos extremos - representar a esa clase social.

\subsection{Movimientos sindicales y movimientos políticos}

El cuadro de la situación se complica cuando ambas organizaciones, sindicatos y partidos, interactúan en el sistema político y cuando, normalmente solamente los primeros, participan del sistema de relaciones laborales. Las relaciones en ambos sistemas implican un tejido histórico de conflictos y consensos, y una creciente institucionalización de los actores.

Los mecanismos político-constitucionales y las leyes laborales institucionalizan a los sindicatos, los hacen formar parte del juego político y económico (sea para asociarlos a determinados proyectos de desarrollo que implican la ampliación del mercado interno y la participación, por ejemplo, o para minimizarlos o quitarles poder si se imponen ajustes que requieran un redimensionamiento del Estado y del mercado) y los convierten en un mecanismo permanente $e$ institucional de control de los trabajadores, llevando la conflictividad social por canales y marcos regulados.

Esta institucionalización puede llevar a muchos sindicatos a compartir áreas importantes de poder, a disponer de estructuras y medios financieros $y$ - en ocasiones - a integrarse formal o informalmente al aparato del Estado.

Cuando este Estado es dirigido por el mismo (o los mismos) partidos que controlan los sindicatos aparecen los fenómenos corporativos o neocorporativos: esos sindicatos que, a pesar del dis- 
curso de representar a los trabajadores, en realidad representan al Estado frente a los trabajadores ${ }^{9}$.

En general ocurre que se encuentran en una posición intermedia entre ambos:

- porque no lograr cierto consenso o legitimación entre sus afiliados o sus bases le llevaría a perder su función de canal o mecanismo de participación (y control),

- y de no tener capacidad de negociación con del Estado o con los empresarios, perderia la posibilidad de obtener "conquistas" que a su vez los legitiman frente a sus bases.

De esta suerte el dirigente sindical suele tornarse un equilibrista permanente y un manipulador de, al menos, tres lenguajes o códigos diferentes para comunicarse, ora con los trabajadores, ora con el partido y el Estado, ora con los patronos, sectores con los intereses en algunos casos comunes pero generalmente contrapuestos $y$ diferenciados en el reparto de la "torta" producida en la economía. Normalmente, nuestro sindicalista maneja, al menos, dos discursos: uno como dirigente obrero y otro como diputado.

La historia y las estructuras del movimiento sindical, pues, están ligadas e interelacionadas a los demás factores y mecanismos del sistema de relaciones laborales y del sistema político, en especial:
- a los partidos y movimientos políticos, a cuyas relaciones ya nos hemos referido,

- al capital toda vez que las estructuras organizativas de los sindicatos suelen construirse como reflejo de las estructuras productivas - determinadas por las decisiones empresariales nacionales y transnacionales y las políticas estatales de fomento, asi por ejemplo, los cambios en la estructura de una rama de la producción producirán un cambio en la organización de los sindicatos e inclusive su desaparición o su fortalecimiento.

Esta estructuración "refleja" o espejo puede ser, en algunos casos, determinante prácticamente inevitable de la estructura; si se cierran las minas de carbón (en Gran Bretaña, Venezuela o Chile, por ejemplo) es lógico que desaparezca el sindicato que agrupa a esos trabajadores.

- al Estado. Se dictan las leyes que primero reprimieron la organización sindical (etapa de la prohibición), después la toleraron (etapa neutra), subsiguientemente la aceptaron y condicionaron (etapa de regulación legislativa) e incluso de dieron rango constitucional y protección internacional (etapa de la constitucionalización) muchas veces coetáneamente con el desarrollo de mecanismos destinados a tratar de integrar y cooptar al sindicato y convertirlo en un órgano

9 La percepción popular de este fenómeno fue muy clara en la Venezuela del período en estudio, aunque su aplicación a todas las estructuras sindicales es, a nuestro criterio, un sofisma de generalización. 
del Estado (etapa neocorporativa). Aquí un elemento diferente al capital juega un papel muy importante: aunque la legislación latinoamericana en general y Venezolana en particular, ha sido abusivamente intervencionista limitando la libertad sindical en la autodeterminación de los sindicatos, es notable que esta limitación también es una autolimitación ideológica que refleja la escasa autonomía de los propios trabajadores y de sus organizaciones y de las ideologías dominantes en el movimiento sindical.

\subsection{Aspectos ideológicos}

Nos parece importante insistir en el arraigo de la idea de autonomía sindical en el campo de las experiencias políticas latinoamericanas. El sindicalismo de algunos de los países de mayor y más temprana implantación en continente, y por ello con una fuerte influencia inicial anarcosindicalista, como México, Brasil, Argentina y Bolivia tuvo una fuerte impronta política de los movimientos nacionales que asociaron a las organizaciones de los trabajadores a procesos de carácter industrializador y redistributivo y que intentaron el reemplazo de las elites oligárquicas del poder político, las nacionalizaciones y la organización estatal de los servicios públicos y la seguridad social.

Estas experiencias significaron en muchos casos la "nacionalización" cultural del movimiento sindical, implantado con el aporte decisivo de los inmigrantes europeos y un salto de los trabajadores a la arena política de la que estaban radicalmente excluidos en los esquemas de las "repúblicas" oligárquicas.
Junto con esa ampliación de la ciudadanía política, se produjo una mayor participación en la producción y en la distribución del ingreso, la aparición o la puesta en práctica de sistemas de jubilaciones, salud y vivienda, el cumplimiento de la legislación protectora, el acceso a la educación y otros avances sociales que colocaron a los trabajadores de esos países en una situación social claramente diferente a la que tenían en la anterior eta$\mathrm{pa}$, sin que ello signifique que los problemas estructurales y la distribución del ingreso hayan cambiado radicalmente.

Los procesos de urbanización y marginalización complicaron y le dieron una nueva faz a la cuestión social. El sindicalismo es percibido como uno de los actores de ese proceso de ascenso social de importantes capas de trabajadores del campo y la ciudad.

De esta suerte, el sindicalismo latinoamericano en general tiene un permanente "dilema" político entre la conservación de su autonomía y las adhesiones políticas a movimientos y partidos cuyos programas y propuestas son policlasistas.

\subsection{El Movimiento Sindical y la conciencia de clase}

Aparece aquí la categoría de la conciencia de clase y las diferentes propuestas filosófico políticas explicativas de la misma y de su relación con la praxis social individual y colectiva de los trabajadores.

En este aspecto, es importante la relación del movimiento sindical con los trabajadores, relación que varía en cada proceso histórico y que se modela según 
los grados de autonomía del sindicalismo y de conciencia de los trabajadores: variará en la medida que los trabajadores tengan una mayor experiencia sindical y política y que existen diversas circunstancias objetivas (desde la concentración de trabajadores en un determinado grado de "ecología proletaria" ${ }^{10}$, el régimen de libertades públicas, el desarrollo tecnológico o el modelo económico imperante, por ejemplo).

Uno de los problemas actuales más interesantes en el análisis de la conciencia de clase y la crisis del movimiento sindical es el desmembramiento de los sujetos colectivos y los cambios de los actores individuales y colectivos con el avance del individualismo por los cambios culturales, tecnológicos y sociales, to cual presenta desafíos impresionantes.

Está naciendo un nuevo arquetipo humano: "parte de su vida la vive cómodamente en los mundos virtuales ciberespacio; conoce bien el funcionamiento de una economía-red, está más interesado en tener experiencias excitantes y entretenidas que en acumular cosas; es capaz de interaccionar simultáneamente en mundos paralelos... Los nuevos hombres y mujeres no son de la misma naturaleza que sus padres y abuelos, de la era industrial" (Rifkin, 1999).

Este nuevo tipo humano presenta desafíos muy importantes no solamente a la organización y programas sindicales, sino, mucho más allá a la familia, a los partidos políticos y otras instituciones que comienzan a ser vistas como obsoletas.

En este sentido, los trabajadores tradicionalmente se organizaban como sujetos colectivos, en cada etapa del desarrollo organizativo, asumían la conciencia de pertenecer a determinada categoría profesional (zapateros, viajantes, sastres etc.), más adelante a determinada rama de producción (metalúrgicos, construcción, mineros etc.), y en un sentido más amplio la identificación de clase (artesanos, trabajadores, obreros...). Una forma orgánica que suele coincidir con procesos de escasa solidaridad clasista es el sindicato de empresa, que cuando se impone como modelo generalizado, en general por las legislaciones laborales más retrasadas, conspira contra la organización sindical de la mayoría de los trabajadores en países como los latinoamericanos en los cuales la morfología del mercado de trabajo muestra un predominio de las pequeñas unidades productivas.

Otra forma organizativa es la local, trabajadores de diferentes sectores que asumen la identidad de su sector 0 área de trabajo, como las Federaciones locales en diversos países, o el caso de los "cordones" chilenos de la época de la UP o los "piqueteros" argentinos actuales.

Las diferentes etapas del desarrollo tecnológico y de las coyunturas políticas

10 Las concentraciones fabriles que reúnen a miles de trabajadores generan una interacción más allá de una fábrica o un grupo de éstas, producen relaciones permanentes entre diversas generaciones de obreros, sus familias, sus sitios de estudio, de recreación, sus clubes y organizaciones mutuales, todo lo cual hace a un ambiente en el cual la organización sindical, más allá del estrecho límite del sitio particular de trabajo, genera una "ecología" proletaria con retroalimentaciones que hacen naturales las estructuras y culturas sindicales desarrolladas. 
contribuían a estas formas de organización e identificación de los trabajadores.

En los Estados Unidos, por ejemplo, tardó más de un siglo la unidad organizativa de los gremios de oficio, que se reunieron en la $A F L$, con los de rama de producción, que se unificaron en la $\mathrm{ClO}$, con la creación del la AFL-CIO en los cincuenta del siglo pasado. Entre nosotros el sindicalismo de oficio, después llamado profesional, era la típica forma organizativa de los grupos anarquistas mientras que las organizaciones por rama eran propuestas por comunistas y después de convirtieron en la base de los grandes sindicatos en las experiencias del sindicalismo de masas en México, Brasil o Argentina.

Estas formas organizativas implican diferentes formas de relación entre los sindicatos y los trabajadores, desde los modelos más claramente democráticos, con democracia directa y asamblearia, como los anarquistas, entre los cuales los dirigentes eran parte de los dirigidos que se destacaban por su laboriosidad, maestría y condiciones morales, hasta modelos autoritarios en los cuales los dirigentes son altamente diferenciados de la masa de sus representados, con mecanismos esporádicos de legitimación y un esquema de relaciones basado en el clientelismo y el economicismo.

En general, a pesar de las grandes diferencias entre los diversos modelos, el funcionario sindical se convierte en un gestor de las reivindicaciones individuales y -ocasionalmente- colectivas de sus agremiados, y comienza a desarrollarse una relación política clientelar, similar a la que de desarrolla en los sistemas políticos.
Ocurre que cambia el marco normativo (por la modificación de las leyes o por la adopción de normas internacionales que permiten la autonomía sindical que deberían aplicarse jurídicamente en forma automática), y sin embargo, los trabajadores y las organizaciones ( $y$ otros componentes del sistema de relaciones laborales) continúan pensando con la mentalidad que se aferra a las normas limitativas de la autodeterminación sindical.

Este esquema sindical suele coexistir y confrontarse 0 integrarse con el también genéricamente denominado sindicalismo clasista, en el cual la relación del movimiento sindical con el Estado es más conflictiva y el poder sindical y la institucionalización suelen ser mucho menores.

En el sindicalismo clasista la relación partido/sindicato suele estar determinada por dos modelos fundamentales: el modelo leninista y el socialdemócrata, en sus diferentes variables. El centro del primer modelo es la idea de la "correa de transmisión" del partido hacia la clase obrera. La política del "brodeurismo" macó la participación de las organizaciones de izquierda en el movimiento obrero de varios de nuestros países en épocas claves de la implantación sindical. Posteriormente a la revolución cubana, en muchos países, el eje político pasó de la lucha política y sindical a la lucha armada, convirtiéndose a los militantes sindicales de esa tendencia en agentes de reclutamiento de cuadros para la lucha guerriliera.

En cambio, el segundo modelo propone la participación de los sindicatos en partidos socialdemócratas o similares, la estrategia de participación parlamentaria y de avance en la correlación de clases, 
cercano en algunos aspectos a algunos modelos nacionalistas, como el esquema argentino de la "columna vertebral", para definir la relación sindicatos / movimientos políticos.

\subsection{Movimiento sindical y movimiento obrero}

Algunos destacados autores han tratado de distinguir entre sindicalismo y movimiento obrero, asignando a la primera denominación un carácter básicamente economicista, "constreñido a la administración de las demandas económicas, sociales $y$ educativas de los trabajadores"mientras que -en esta concepción- el movimiento obrero "buscará transformar el lugar de la clase obrera en la estructura socialy darle a los trabajadores una voz y un voto en el proceso de toma de decisiones de la sociedad" (Zapata, 1993).

Creemos que esta distinción es equivoca, en primer lugar porque no refleja la que está instalada en la terminología de la mayoria de nuestros países, en donde se suele usar indistintamente movimiento obrero, movimiento sindical, movimiento de los trabajadores, con diversas acepciones y matices, aunque en este último concepto suelen incluirse organizaciones de tipo barrial, étnico etc.

Se trata de dos formas o concepciones del sindicalismo, que dependen del desarrollo político de las organizaciones.

Existirá, pues, un sindicalismo economicista o meramente reivindicativo y un sindicalismo como movimiento políti$\mathrm{co}$, parte de movimientos nacionales o ligado a partidos clasistas o policlasistas, $y$ por ende con participación política. Como solia afirmarse en las épocas anteriores al postmoderno "desprestigio de la política": no hay sindicalismo "apolítico", los apolíticos suelen coincidir con la política de los patronos.

Ya hemos dicho que en muchos de nuestros paises, el movimiento sindical ha jugado un papel muy importante en los procesos reales de construcción de los proyectos nacionales transformadores, que fueron reemplazando la dominación oligárquica (Massardo, 2000) por modelos industrializadores dentro del esquema desarrollista de sustitución de importaciones que, a su vez, permitieron con sus éxitos y fracasos, la formación de los sectores sociales que son la base social del movimiento.

En América Latina es común escuchar con mayor o menor veracidad histórica, que los partidos fundaron los sindicatos, pero ahora la tendencia parece revertirse, con la creación de partidos políticos por parte del movimiento sindical, cuyo caso más claro es en Brasil el Partido de los Trabajadores. Los ejemplos más importantes en Venezuela los podemos encontrar en el Partido del Congreso del Trabajo, cuando José González Navarro era presidente de la CTV y que después intregraría el Movimiento Electoral del Pueblo y más recientemente el Partido formado sobre la base de sindicatos de obreros industriales, en su origen especialmente en Guayana: Causa R. Pero como en muchas otras ocasiones no estamos inventando nada: es le modelo del Labor Party, creado por el Trade Unions Congress en la Gran Bretaña, claro que con las características propias de nuestras realidades nacionales y, en los casos 
aludidos, con una lucha simultánea contra una estructura política "oficial" en sus orígenes.

Este desarrollo político suele acompañarse con el desarrollo organizativo: el movimiento sindical en la arena política desarrolla estructuras que lo identifican con el sindicalismo de masas: ha desarroliado el paso del sindicalismo de cuadros al sindicalismo de masas, generando una institucionalidad sindical $y$ un "aparato".

Pero creemos que también es equívoca la diferenciación a la que haciamos mención, porque en el proceso gradual de organización de los trabajadores, la "primera oleada" - históricamente hablando - fueron los obreros urbanos y de los sectores de la minería, de las industrias de bienes exportables y del transporte, el proletariado como se los denominaba en la Europa del siglo pasado y en los años iniciales de nuestras organizaciones laborales latinoamericanas, fuertemente influenciadas por la migración.

Pero, en una segunda ola de organización se van sindicalizando los trabajadores no manuales o empleados, los trabajadores de los servicios y los asalariados rurales y más adelante en una tercera oleada, los profesionales y técnicos, los funcionarios públicos y los trabajadores informales, generando un conjunto complejo de experiencias colectivas que confluyen en el concepto general de movimiento sindical, aunque en ese proceso algunas de las organizaciones no hayan asumido plenamente la forma sindical.

El calificativo de "obrero" parecería provenir de un reduccionismo que predo- minó en muchas corrientes sindicales que propugnaron dogmáticamente la "vanguardia" de los sectores obreros, que durante muchos años tuvieron un papel muy importante por su mayor experiencia, por la "centralidad" de la fábrica y la capacidad organizativa que otorgaba la concentración en zonas industriales o mineras: la ecología proletaria.

Históricamente no hay ninguna correlación mecánica entre el origen obrero $o$ no obrero de los componentes de una organización sindical y su desarrollo político: muchos sindicatos cuyos afiliados son predominantemente "proletarios" tienen un desarrollo político escaso, son meramente economicistas y, en cambio, sindicatos de trabajadores rurales o de empleados públicos pueden tener una importante autonomía y un destacado papel en proyectos de transformación de la sociedad.

Más aún, en el fondo las concepciones "obreristas" suelen esconder dos graves problemas:

- un "corporativismo" obrero, propio de lo que se ha denominado la "aristocracia obrera" y que se articula con

- la idea de la vanguardia "externa" por la cual la clase obrera necesita del partido (que "representa" sus intereses históricos) para "ayudarla" avanzar políticamente en la sociedad.

Esta concepción, en el fondo, representa una variante del subdesarrollo político del movimiento sindical: los sindicatos tienen un papel económico-reivindicativo y su aspecto político es el de ser la correa de transmisión del partido. Este es uno de los capítulos más interesantes de la ciencia política: el de la relación entre los partidos y los sindicatos, no solamente en Venezuela y en nues- 
tro continente (y uno de los campos en los cuales deberiamos revisar los dogmas y los paradigmas que han imperado) ${ }^{11}$.

\section{La crisis del movimiento sindical. los efectos de la mundialización}

\subsection{Crisis política, del modelo de desarrollo y crisis sindical}

La crisis del movimiento sindical en nuestra región tuvo directa relación con la crisis del modelo de desarrollo de industrialización sustitutiva de importaciones y la del tipo de Estado con el que políticamente explícita o implícitamente se asoció el sindicalismo en ese período.

Es el momento de situar diacrónicamente "el momento" de la crisis sindical en el ámbito mundial: nuestra propuesta la sitúa en la década de los ochenta.

En 1980 la tasa de sindicación en los Estados Unidos era del $20,4 \%$ y en 1986 se habia reducido a un $14 \%$ : es decir había disminuido más de en un punto porcentual por año Organización Internacional del Trabajo (OIT, varios años).

De persistir esa tendencia, en forma mecánica - lo que no es técnicamente posible - se podría haber pronosticado que este año, el año 2000, habría desaparecido en los Estados Unidos en último trabajador sindicalizado, como antes se había extinguido en ese país "el último moicano" (Iturraspe, 1999 b). Pero la tendencia no era solamente en ese país, en períodos similares las tasas se habian reducido en Canadá, Italia, Holanda y el Reino Unido e iguaimente en varios países de América Latina.

En el período en estudio, entonces, coincide el proceso de retroceso sindical en todo el mundo con el agotamiento en Venezuela y América Latina en general del modelo de sustitución de importaciones y la aparición del de economía abierta que se ha dado en denominar neoliberal. Es la época en la que también comienza a desarrollarse la profundización del proceso de mundialización y una aguda crisis politica y cultural que afecta a los paradigmas y al modo de vida que se habían desarroliado durante los treinta años dorados de crecimiento de la economía mundial.

Podríamos afirmar que, además, también es en esa etapa en la cual hacen crisis las concepciones ideológicas dominantes en nuestros sindicatos $y$, por la acción de los cambios en el mercado de trabajo, hay profundos cambios en los sectores sociales que habitualmente conformaban las bases de la organización, más allá de los problemas de los sujetos colectivos a los que haciamos referencia.

11 El desprestigio del modelo del centralismo democrático, los graves probiemas de los sindicatos socialdemocrátas sobre todo frente a los gobiernos laboristas y socialistas de la "tercera vía", la posiciones neoliberales adoptadas por gobiernos latinoamericanos vinculados a los sindicatos, cuyo ejemplo entre nostros es el de Carlos Andrés Pérez a finales de los ochenta, sumados a la grave crisis general de la representatividad a nivel mundial ponen la relación sindicatos-partidos-Estado en una situación inédita por las crisis de las tres instituciones y por ello es frecuente en la literatura encontrar propuestas para "reinventarlas". 
Por ello es que nos proponemos describir someramente las últimas etapas del desarrollo del movimiento sindical para tratar de entender a qué movimiento sindical concreto se le aplica la crisis que trae aparejada la mundialización y cuáles son las posibilidades que trae esa crisis.

La mayoría de los textos de historia del movimiento sindical en América Latina terminan cuando empieza la mundialización: A partir de allí hay un salto y aparecen en la bibliografía intemacional las especulaciones sobre el futuro, una prospecta que se desarrolla en un péndulo que va desde los augurios de su desaparición con el "fin del trabajo"(Rifkin, 1999) hasta los felices horóscopos de la construcción de "máquinas revolucionarias politicas, teóricas, libidinales y estéticas" que nos propone Guattari (1989).

\subsection{Los efectos de la mundialización: La crisis de la centralidad del trabajo y el agravamiento de la brecha entre pobres y ricos}

Si bien el taylorismo y el fordismo tuvieron una implantación desigual y relativamente restringida entre nosotros, la nueva etapa ha impactado seriamente a nuestras sociedades, tanto con su aporte a las distorsiones del mercado de trabajo (aumento del desempleo, disminución del salario real, desregulación, precarización e informalidad) como con sus impactos culturales y políticos: el principal enemigo del movimiento sindical es el desempleo.

Con mercados de trabajo como el venezolano, con una informalidad que abarca la mayoría de la fuerza laboral y altas tasas de desempleo, la legítima de- fensa de intereses los trabajadores empleados-formales representa, a los ojos gran parte de la sociedad, la pugna corporativa por privilegios.

Los actores sociales pierden influencia frente al mercado que, en las actuales condiciones de la oferta y la demanda "locales" y del dumping social internacional, tienden a aumentar los efectos perversos sobre la equidad social: prácticamente en todos nuestros países la "brecha" entre los sectores sociales privilegiados y los marginados es cada vez mayor generándose una potenciación de las desigualdades heredadas de los períodos anteriores.

Nuevamente en este caso, las desigualdades sociales que se agudizan cada vez más permiten un reagrupamiento de los actores sociales, nuevas formas de articulación entre los antiguos y emergentes protagonistas, así como la preocupación creciente frente a la "nueva cuestión social" por parte de diversos sectores preocupados por la "gobernabilidad".

La crisis del Estado-Nación y de los actores sociales. Los ajustes y la apertura de nuestros países forman parte de un proceso de transformación social, económica, financiera, política, cultural y comunicacional a escala internacional, que se ha denominado"globalización" o, más castizamente, mundialización (Iturraspe(ed.)1999 b).

Los Estados-nación parecen haber perdido el control de la situación - y según muchos observadores y protagonistas la economía global ha transpuesto de tal forma las fronteras que los Estados se ven sobrepasados.

En efecto, el mundo en general y la región en particular viven un proceso de 
deterioro acelerado del poder del Estado-nación, desigualmente manifestado y causado por una multiplicidad de procesos:

La pérdida creciente de poder económico frente a las empresas transnacionales $y$ frente al impresionante aumento del comercio mundial, sobre todo entre los países desarrollados. En nuestros paises la deuda externa ha colocado a nuestras economías en una situación muy comprometida frente a los centros financieros internacionales. Gran parte de los presupuestos públicos están afectados al servicio de las obligaciones internacionales contraídas. En los países desarrollados los aportes impositivos de las empresas transnacionales al fisco son cada vez menores, mientras los requerimientos sociales crecen. Entre nosotros, con una presión impositiva menor, el cúmulo de los problemas acumulados de las anteriores etapas y magnificados por el neoliberalismo es aún mayor.

Comienza a ser erosionado, en todas partes, por los regionalismos y las autonomías, resquebrajando su monolitismo como se ha puesto de manifiesto dramáticamente en Europa en estos últimos años. Los procesos de descentralización "acercan" al Estado a la población y lo hacen más accesible pero también más vulnerable.

Se ve afectado por los procesos de integración y la creación de zonas de libre comercio que implican una clara reducción de la idea tradicional de soberanía y traen consigo cambios significativos en la posición, funciones y estructuras del Estado. Sin embargo, frente a esta crisis del actor estatal, la integración parecería también un mecanismo ineludible para enfrentar en común los problemas bási- cos de nuestras sociedades, desde una perspectiva común y abandonando cierto provincialismo que conspira contra la eficacia de las políticas sociales.

La pérdida del control de las comunicaciones y de la cultura, dentro de la "aldea global" y el fortalecimiento de grandes transnacionales de las comunicaciones con la posibilidad de llegar, merced a la difusión de las nuevas tecnologías satelitales a cualquier lugar del planeta.

La crisis del Estado "por dentro" en el doble orden de sus relaciones con sus trabajadores (antes "servidores" sujetos a rígidas normas estatutarias y ahora permeado por la convención colectiva y la organización sindical) y con sus ciudadanos (antes súbditos) cada vez más atentos a sus derechos y prerrogativas frente al aparato estatal, gracias a una formidable toma de conciencia sobre los derechos humanos y la defensa del ambiente, una de las transformaciones más importantes de nuestro siglo que, por una parte, limita el poder del estado $y$, por otra muy importante, pone de manifiesto sus limitaciones para hacer cumplir las regulaciones.

Los procesos de privatización y racionalización tienen como meta reducir en algunos casos drásticamente - el tamaño del Estado y su inffuencia. En América Latina aparece claramente esta tendencia, aunque también comienzan a producirse importantes reacciones.

Una fuerte crisis ideológica de las ideas estatistas en todas sus concepciones y, por el contrario, la hegemonia de concepciones neoliberales y postmodernas que suponen la satanización de lo estatal y el desprestigio de la política como actividad social. 
Una notable "revolución de las expectativas" crecientes de la población que, por otra parte, ve dificultada su atención por las crecientes limitaciones financieras originadas en reducciones fiscales y las evasiones hacia los paraísos financieros.

De esta suerte, dentro de las expectativas que mencionábamos, las demandas que diferentes sectores hacen al Estado frente a problemas sociales muy importantes como los del empleo, cada vez tienen una menor posibilidad práctica de ser resueltos por la vía del paternalismo estatal, en especial en los paises de menor desarrollo relativo. Frente a esta los Estados recurren al financiamiento y asesoramiento de las instancias transnacionales, que pasan a tener un gran poder de decisión en la política social.

Por otra parte, la apertura económica cambia radicalmente las reglas de juego en la puja distributiva entre el capital y el trabajo, de la cual el Estado era él arbitro que equilibraba, a través de la política laboral, un balance entre el costo de la mano de obra y la necesidad de crear y mantener un mercado que demande los productos creados por la industria substitutiva de importaciones.

\subsection{La crisis del Estado-Nación y los actores sociales}

En la economía "global", en esa puja distributiva de la ganancia participan ahora actores externos, además de los trabajadores y empresarios del propio país, porque al internacionalizase el mercado de trabajo todos los empresarios y trabajadores (de todos los países) participan de esa competencia. De esta mane- ra, tanto el empleo como el salario se pueden ver afectados por una carrera que fije los precios y el volumen de la fuerza de trabajo de acuerdo a las ofertas más bajas y desprovistas de beneficios sociales: es lo que se ha dado en denominar el dumping social (Iturraspe(ed.)1998b).

"Ya no son solamente las empresas, sino también las ciudades, las regiones y los países los que tienen un rol en este proceso de apertura y competitividad internacional, si entienden bien las reglas. Les bastará a invitar a instalarse a la inversión..., reducir las restricciones a un mínimo y proveer una mano de obra bien adiestrada con infraestructura moderna...Los Estados, las regiones, las ciudades, los municipios se han transformado en postores para la instalación de una nueva fábrica, o lo que es más frecuente, para el mantenimiento de una existente, que una sociedad multinacional podría deslocalizar. Si la comunidad afectada puede ofrecer suficientes ventajas - rebajas fiscales, subvenciones, becas de formación - o si el sindicato de la fábrica acepta las exigencias de la dirección, la fábrica podrá continuar localizada allí hasta que otra oportunidad más propicia se le presente afuera. Las comunidades locales y los sindicatos de las diferentes regiones se disputan los mismos empleos sobre la base de concesiones. De ello deriva que el mejoramiento o el mantenimiento del empleo en alguna parte significa un aumento de la cesantía en otra parte" (Chonchol, 2000).

La crisis del modelo de industrialización por sustitución de importaciones trajo consigo las aperturas económicas y la aplicación de los modelos 
neoliberales que introdujeron la desregulación laboral fáctica o legal, una tendencia a la individualización de las relaciones de trabajo con la preeminencia del mercado sobre las relaciones colectivas, la reforma de la seguridad social para convertirla en mecanismos individuales de capitalización e instrumentos de ahorro forzoso con vistas a la acumulación del capital. Muchos piensan que esta etapa también está en crisis, sobre todo después de la crisis del sudeste asiático y la creciente reacción mundial contra las políticas globalizadoras.

Estamos frente a cambios substanciales que están modificando profundamente nuestra visión del mundo y nuestra sociedad y que, por supuesto, están afectando radicalmente al movimiento sindical (Iturraspe(ed.)1998a; Hernández y Romero, 2000).

\section{Reflexiones o ideas finales}

\section{1. ¿Qué es lo que puede hacer el Estado - y lo que no debería hacer - de acuerdo a la doctrina de la OIT adoptada por la Constitución?}

Específicamente el artículo 3 del Convenio 87 establece que los sindicatos tienen el derecho de elegir libremente a sus representantes... y que "Las autoridades públicas deberán abstenerse de toda intervención que tienda a limitar este derecho o a entorpecer su ejercicio legal". mucho menos puede el Estado convocarie elecciones a los sindicatos (Goizueta $\mathrm{He}$ rrera, 2000).

El Estado no puede dictar disposiciones legislativas que regulen detalla- damente el funcionamiento interno de las organizaciones de trabajadores y empleadores, estas normas entrañan graves riesgos de injerencia por las autoridades públicas. En cambio si puede legítimamente reglar cómo y cuándo se elegirán los trabajadores que participen de los directorios de sus empresas, siempre y cuando no excluyan a las organizaciones sindicales de participar en esas elecciones, porque esa exclusión sería discriminatoria.

Pero el Estado no puede decirle a los sindicatos cuándo van a elegir sus dirigentes o si se van a unificar o no. Esto, que es la esencia de las normas propuestas reiteradamente, al menos en algunas de las versiones sucesivas que hemos revisado, es inconveniente además de contrariar la letra y el espíritu del artículo 95 de la Constitución.

Es evidente que, dentro de los parámetros legítimamente establecidos en la Constitución, es en los estatutos y reglamentos sindicales -dictados por los propios sindicatos en ejercicio de la autonomía normativa o autoregulación- dónde se establecerá dónde, cuándo y cómo se desarrollaran las elecciones y quiénes pueden participar en ellas.

Sin embargo, a principios de octubre, con 106 votos a favor, la Asamblea Nacional (AN) aprobó un decreto que permitió realizar una consulta popular el 3 de diciembre, sobre la convocatoria de una Asamblea Constituyente Sindical, a fin de democratizar y reunificar el movimiento obrero del país.

El proyecto contó con el visto bueno de las bancadas del MVR, MAS, Proyecto Venezuela y COPEI, mientras que los diputados de Acción Democrática, 
Primero Justicia, Alianza Bravo Pueblo y Convergencia (escisión de CO$\mathrm{PEI}$ con otros grupos menores Caldereistas) salvaron su voto. Cabe destacar que el diputado de Causa R, Andrés Velázquez, propuso que el acuerdo sea publicado en un diario de circulación nacional, recomendación que fue aprobada por la mayoría de los diputados. Según el proyecto aprobado, la Asamblea Nacional (Poder Legislativo unicamenral en la nueva Constitución) no va a hacer los estatutos de la Asamblea Constituyente de Trabajadores, pues esta responsabilidad recaerá en el poder electoral. El organismo electoral, después de una batalla legal resuelta por el Tribunal Supremo, puso en marcha los mecanismos que permitieron llevar a cabo el referéndum conjuntamente con las elecciones locales del 3 de diciembre. La participación popular en el mismo fue realmente escasa, inferior al $90 \%$. El Consejo Nacional electoral, a fines de diciembre de 2000 resolvió convocar en enero de 2001 las elecciones sindicales "desde el Estado".

\subsection{Representatividad sindical}

La representatividad sindical es prioritariamente, un problema de los trabajadores. Dicho así, en pocas palabras, esa es la base de la doctrina sindical originaria y contemporánea y de la idea de libertad sindical que viene imponiéndose como un derecho humano fundamental.

De esta manera, la idea de "relegitimar" el movimiento sindical ha sido uno de los ejes de la discusión en el sindicalismoy - mucho menos - entre los trabajadores, aunque la participación real de los interesados directos parece ser poco signi- ficativa. Efectivamente, todo el proceso neocorporativo parece haber tenido un efecto antiparticipativo aún mayor que el previsto por los más distinguidos politólogos (Rey, 1987), al menos entre los trabajadores.

Creemos que es fundamental para los diversos sectores en pugna un cambio radical de actitud que permita "reinventar" un movimiento que enfrente a los grandes cambios y desafíos de la sociedad venezolana del nuevo milenio y que proponga nuevos esquemas organizativos que "reencanten" a los trabajadores, que les hagan propuestas que sean capaces de movilizar más allá de los estrechos y anticuados modelos corporativos. Quizás el viejo concepto de legitimidad dentro del modelo sea ya anticuado y haya que seguir, en este como en otros campos la desafiante idea de Simón Rodríguez: "o inventamos a erramos"

Sin embargo, un Estado democrático tiene muchas formas legítimas de garantizar la representatividad sindical fundamental para el desarrollo de relaciones de trabajo saludables, justas y eficaces - sin interferir en la vida interna de las organizaciones, en la elección de sus dirigentes etc.

Varios paises de Europa, por ejemplo, regulan en su legislación diversos mecanismos que garantizan la democracia y la representatividad sin desmedro de la libertad sindical. Si queremos democratizar y promover el movimiento sindical hagámoslo en serio. Aún desde el Estado se puede promover, desde abajo, la organización laboral, mediante mecanismos cogestivos. Pero para ello hay que atravesar algunas dificultades con la contraparte social del sindicato, con las em- 
presas y con el Estado empleador, específicamente.

Se trata, por ejemplo, de los Comités de Empresa de España, Francia y otros paises, así como los establecidos por una directiva comunitaria europea (94-95). Dentro de unas propuestas que discutimos en Julio del 99 en Sindicato Nacional de Trabajadores de la Prensa convocados por la Asociación Venezolana de Abogados Laboralistas y en la que participaron, por ejemplo, Isaías Rodriguez, León Arismendi, Juan Rafael Perdomo, César Bustamante, estaba la de incluir en la Constitución los Comités de Empresa, como instrumento de democratización sindical desde abajo.

En las empresas 0 instituciones con una cantidad determinada de trabajadores, cincuenta o más por ejemplo por el tamaño de nuestras empresas, los trabajadores sin distinción alguna, afiliados o no a un sindicato, deberán elegir entre sus compañeros sus representantes a un comité de empresa que tiene por funciones fundamentales vigilar el cumplimiento de las normas laborales, colaborar en la gestión de la empresa etc. En las empresas más pequeñas se puede elegir un delegado y un suplente, por ejemplo. Todos tiene derecho a participar y los candidatos de diferentes sindicatos se "cuentan" en cada elección. Es frecuente que en tal o cual comité participen trabajadores y trabajadoras de la Unión General de Trabajadores (UGT) o a las Comisiones Obreras con otros independientes en España. Las elecciones se realizan en un soio día y previa campañas muy interesantes, con programas y propuestas, debate de ideas.
Sin ir muy lejos, nosotros tenemos una institución de naturaleza cogestiva parecida - y escasamente jerarquizada y desarrollada - que son los Comités de Higiene y Seguridad establecidos por la Ley Orgánica de Prevención.

Hubiera sido muy positivo establecer los Comités de Empresa constitucionalmente, pero igualmente se pueden establecer ahora por Ley basándonos en el artículo 70 de la Constitución que dice:

Son medios de participación y protagonismo del pueblo en ejercicio de su soberanía, (...) en lo social y económico, las instancias de atención ciudadana, la autogestión, la cogestión, (...).La ley establecerá las condiciones para el efectivo funcionamiento de los medios de participación previstos en este artículo.

De esta manera, el Estado puede hacer que ia democracia y la representatividad se garanticen, desde abajo, por los propios trabajadores. Los Comités de Empresa se articulan con los sindicatos, que continúan con la titularidad de la negociación colectiva, y que le dan el carácter pluralista a los Comités.

\subsection{Ciudadania productiva}

Pero todo esto debería ir acompañado por un marco de desarrollo de una nueva mentalidad participativa de los trabajadores y empleadores, del desarrollo de lo que hemos denominado la ciudadanía productiva. Los trabajadores no pueden limitarse a la ciudadanía política: deben devenir en ciudadanas y ciudadanos de la empresa, en protagonistas del esfuerzo productivo y también en acreedores de la justa distribución de la producti- 
vidad. Esa es la base de la justicia socialy de la redistribución del ingreso.

Los Comités de Empresa deberían ser el órgano fundamental de la ciudadanía productiva, y el empresariado-por lo menos un sector importante - debería considerar favorablemente - una propuesta que permita mejorar la competitividad y el ambiente laboral.

De esta suerte, más allá de las rencillas políticas - muchas veces justificables - los trabajadores tendrán como eje de los debates y de las aspiraciones los logros cotidianos, la defensa de sus derechos y la construcción de su propio porvenir.

Otro mecanismo interesante es en Francia la elección por los trabajadores de los jueces laborales que los representan en los tribunaies de "Prud hommes". Una versión "desarrollada" de nuestras antiguas comisiones tripartitas, pero electas democráticamente, en elecciones nacionales en las que participan todos los trabajadores y también se realizan simultáneamente. Son la base de un sistema de justicia laboral de legendaria eficacia.

Como vemos, el Estado puede establecer mecanismos de elección directa, secreta y universal de representantes de los trabajadores en sus propios órganos, por ejemplo, en una comisión para determinar concertadamente el salario mínimo, porque este es un órgano del propio Estado.

\subsection{Sector Público}

Para el sector público parece urgente restaurar el espíritu de la Ley de
Carrera Administrativa, en el sentido de un cuerpo profesional de servidores del Estado, más aliá del clientelismo político de tal o cual gobierno.

El problema en la Administración Pública, como en tantas otras esferas de la vida ciudadana, es el incumplimiento normativo reiterado. Claro, sobre la base de esta distorsión, los sindicatos y la negociación colectiva en el sector, cuyo ejercicio es una garantía reiterada en la Constitución, han devenido en sistema insostenible.

Debería pues aprovecharse esta oportunidad para sanear el sistema, aplicando las leyes, concursando a los funcionarios y -quizás- estableciendo un sistema de representación directa de los empleados y obreros en unos Consejos similares a los de la administración pública británica, los consejos Whitley, en los cuales, los trabajadores participen directamente en la auto reforma de los servicios. Se trata de hacer -me perdonan la expresión- una "reingeniería" de todo el Estado para adaptarlo a una normativa jurídica que garantice la profesionalización y la mística de servicio público de los funcionarios y que sea la base de un sistema de relaciones laborales democrático, eficiente y no clientelar.

Estos Consejos de reforma deberian tener representantes electos directamente por los trabajadores de cada sector del funcionariado, los cuales, junto a los representantes de las autoridades públicas, revisen los mecanismos de selección, ingreso, participación, la propia negociación colectiva y busquen un modelo democrático de relaciones laborales para el sector, de acuerdo al Convenio 151 de la OIT. 
Dentro de la transición parecería que el acuerdo logrado tras la huelga petrolera de octubre de 2000, la escasa participación popular en el referéndum del 3 de diciembre y la posterior renuncia colectiva de la dirección de la CTV, nos colocan frente a una nueva perspectiva en la que es posible que se pueda conciliar la democracia sindical con la autonomía sindical, lo que creemos parece ser el imperativo de la actual hora del mundo del trabajo entre nosotros: son objetivos compatibles y ojalá los trabajadores y los legisladores encuentren el camino para hacerlo.

\section{Bibliografía citada}

Chen, Chi Yi (1994). Mercado Laboral. Teorías y Políticas UCAB, Caracas, (4ta. edición).

Chonchol, Jacques (2000). ¿Hacia dónde nos lleva la globalización? ARCISLOM, Santiago.

Goizueta Herrera, Napoleón (2000). El referendo sindical y la libertad y democracia sindical, ponencia al foro de la Asociación Venezolana de Proiesores de Derecho del Trabajo y de la Seguridad Social, 30 de Noviembre, Maracaibo.

Guattari, Féix (1989). Cartografías del deseo Francisco Zegers, Santiago de Chile.

Hernández, Oscar y Romero, Antonio (2000). "Sindicatos en tiempos globalizados: el caso venezolano" en revista Compendium, Nro. 4, UCLA, Mayo.

Iranzo, Consuelo (1996). "Respuestas del movimiento sindical venezolano del sector público frente a la reestructuración económica" en: Carlos ALÁ SANTIAGO y Elsa PLANELL LARRINAGA (ed.). Reestructuración productiva, cambio tecnológico, género y sin- dicalismo en América Latina-ALST-Universidad de Puerto Rico, San Juan de Puerto Rico.

Iranzo, Consuelo (et alt.) (2000). "Reestructuración Económica y Mercado de Trabajo en Venezuela". Clacso en imprenta, Buenos Aires.

Iturraspe, Francisco (1993). "Intervención del Estado y autonomia en las relaciones colectivas de trabajo en Venezuela" en Oscar Ermida Uriarte(coord.), Intervención y autonomía en las relaciones colectivas de trabajo, FCU, Montevideo.

Iturraspe, Francisco (ed.) (1998a). Empleo un reto para el crecimiento UNESCOSELA, Caracas.

Iturraspe, Francisco (ed.) (1998b). Glabalización, integración, dumping social y cláusulas sociales UCV, Caracas.

Iturraspe, Francisco (ed.) (1999 a). Desarrollo y crisis del movimiento sindical. Tercera Edición, UCV, Caracas.

Iturraspe, Francisco (ed.) (1999 b), Los derechos de los trabajadores en la era de la mundialización UCV, Caracas.

Iturraspe, Francisco (ed.) (2000). "Democracia y autonomía sindical: ¿cómo conciliar dos metas valiosas?" en SIC, año LXIII \#622, Caracas, Marzo.

Lucena, Héctor (2000). Reestructuración política y regulatoria de las relaciones laborales venezolanas mimeo, ponencia presentada al III Congreso de ALAST, Buenos Aires. Mayo.

Massardo, Jaime (2000). Notas para una discusión a propósito de la historia contemporánea de América Latina mimeo, Santiago de Chile

Melgar Bao, Ricardo (1988). El Movimiento Obrero Latinoamericano Alianza Editorial, Madrid.

OIT, Publicaciones (El Mundo del Trabajo, varias ediciones), Ginebra, Suiza. 
El sindicalismo en el contexto de la globalización

Iturraspe, Francisco

Parra Aranguren, Femando Ignacio (1997). "Ideas en tomo a la negociación colectiva como resultado y como proceso"en Revista de la Fundación Procuraduría, número 17, Caracas, pp.135 a 164 .

Rey, Juan Carlos (1987). "El futuro de la democracia en Venezuela" en Venezuela hacia el año 2000, Nueva Sociedad, Caracas.

Rifkin, Jeremy (1999). El fin del trabajo Paidós, Buenos Aires (5ta. reimpresión)

Rifkin, Jeremy (2000). "La nueva era del acceso"Versión de Clarín Digital, Buenos Aires, octubre.
Romero, Antonio (1997a). Legitimidad y representatividad del sindicalismo en Venezuela, UCLA, Barquisimeto.

Romero, Antonio (1997b) . Cronología y análisis de las huelgas en Venezuela, UCLA, Barquisimeto.

Valecillos, Héctor (1990). Economía y política del trabajo en Venezuela Academia Nacional de Ciencias Económicas, Caracas.

Zapata, Francisco (1993). Autonomía y subordinación en el sindicalismo latinoamericano Fondo de Cultura Económica, México. 